\title{
Effects of Intercropping Density of Galinsoga parviflora on Cadmium Accumulation of Soybean
}

\author{
Lijin Lin ${ }^{1, a}$, Fiyi Tang ${ }^{2, b}$, and Ming'an Liao ${ }^{2, c^{*}}$ \\ ${ }^{1}$ Institute of Pomology and Olericulture, Sichuan Agricultural University, Chengdu, Sichuan, China \\ ${ }^{2}$ College of Horticulture, Sichuan Agricultural University, Chengdu, Sichuan, China \\ allj800924@163.com, btfy1961@163.com, Iman@sicau.edu.cn \\ ${ }^{*}$ Corresponding author
}

\begin{abstract}
Keywords: Intercropping; Cadmium accumulation; Galinsoga parviflora; Soybean
Abstract: The effects of intercropping different density (1, 2, 3, 4 and 5) of cadmium (Cd) hyperaccumulator Galinsoga parviflora on cadmium accumulation of soybean were investigated through pot experiment. The results showed that intercropping with $1 \mathrm{G}$. parviflora seedling increased biomass of soybean compared with monoculture, and decreased when intercropping with 2, 3, 4 and 5 G. parviflora seedlings. Intercropping with different density of $G$. parviflora decreased Cd content in soybean compared with monoculture, and the more number of $G$. parviflora, the lower Cd content in soybean. When the density was not more than 3, intercropping with soybean increased biomass of $G$. parviflora, and decreased $\mathrm{Cd}$ content in $G$. parviflora. Intercropping with soybean increased $\mathrm{Cd}$ extraction by G. parviflora. Therefore, the best density of G. parviflora to intercropping with soybean was 1 , which could be used in the Cd-contaminated soil for the phytoremediation.
\end{abstract}

\section{Introduction}

In agricultural production, the intercropping is used improve soil nutrients, water and light resources using efficiency of crop, and thus improve the yield and quality of crop [1-2]. Under heavy metal contamination conditions, when roots of two plant species close or touch, the phenomenon of "rhizosphere talk" could produce between two plant spaces, which could promote or inhibit plant growth and heavy metal accumulation [3-5]. When hyperaccumulator Sedum alfredii intercrops with common plants maize and ryegrass respectively, the Zinc $(\mathrm{Zn})$ accumulation in $S$. alfredii increase significantly, and cadmium $(\mathrm{Cd})$ and $\mathrm{Zn}$ contents in maize and ryegrass reduce significantly [6]. The other studies have the same results [7-8]. Galinsoga parviflora is a cadmium (Cd) hyperaccumulator [9], and soybean is an important common crop. To decrease the Cd content in soybean that growing in Cd-contaminated soil, the effects of intercropping different density of Cd-hyperaccumulator $G$. parviflora on $\mathrm{Cd}$ accumulation of soybean were investigated in this study. The aim of the study was to screen intercropping density of $G$. parviflora which could decrease Cd content in soybean and keep yield of soybean, and provide a reference for other crops.

\section{Materials and Method}

Materials. The inceptisol soil samples were collected from Ya'an campus farm of the Sichuan Agricultural University $\left(29^{\circ} 59^{\prime} \mathrm{N}, 102^{\circ} 59^{\prime} \mathrm{E}\right)$, China, in March 2014 . The basic properties of the soil were the same as reference [9], and the total Cd content was $0.101 \mathrm{mg} / \mathrm{kg}$. G. parviflora seedlings with two pairs of euphyllas were collected from the Ya' an campus farm (from uncontaminated soil) in April 2014.

Experimental Design. The experiment was conducted at the Ya'an campus farm from March to Jun in 2014. The soil samples were air-dried and passed through a 5-mm sieve. Three kilograms of the air-dried soil was weighed into each polyethylene pot (15 cm high, $18 \mathrm{~cm}$ in diameter). Cd was added to soils as $\mathrm{CdCl}_{2} \cdot 2.5 \mathrm{H}_{2} \mathrm{O}$ at $10 \mathrm{mg} / \mathrm{kg}$. The soils were mixed immediately and again after 4 weeks, during which soil moisture was kept at $80 \%$. Two uniform seedlings of soybean with one euphylla and corresponding density of $G$. parviflora seedling were transplanted into each pot. The density was 0 
(monoculture), 1, 2, 3, 4 and 5 seedlings of G. parviflora, and each treatment was replicated five times using a completely randomized design with $10-\mathrm{cm}$ spacing between pots. The soil moisture content was maintained at $80 \%$ of field capacity from the time the plants were transplanted into the pots until the time the plants were harvested.

Sample Analysis. One month (after 30 d) later, the plants were gently removed from the soil. The roots and shoots of $G$. parviflora and soybean were harvested and washed with tap water. The roots were immersed in $10 \mathrm{mM} / \mathrm{L} \mathrm{HCl}$ for $10 \mathrm{~min}$ to remove $\mathrm{Cd}$ adhering to the root surface. Then, the treatments and analyses of plants were described as in reference [9].

Statistical Analyses. Statistical analyses were performed using SPSS 13.0 statistical software (IBM, Chicago, IL, USA). Data were analyzed by one-way analysis of variance with least significant difference at a $5 \%$ confidence level.

\section{Results and Discussion}

Biomass of Soybean. After intercropping with G. parviflora seedling, the biomass of soybean was different from monoculture (Fig. $1 \mathrm{~A}, \mathrm{~B}$ ). When intercropping with $1 \mathrm{G}$. parviflora seedling, the root biomass of soybean increased, which increased by $9.40 \%(p<0.05)$ compared with monoculture (Fig. 1 A), indicating that there would be a balance between $G$. parviflora and soybean which could promote soybean growth. However, when intercropping with 2, 3, 4 and $5 \mathrm{G}$. parviflora seedlings, the biomasses of soybean were decreased, which decreased by $19.91 \%(p<0.05), 30.77 \%(p<0.05)$, $37.61 \%(p<0.05)$ and $40.64 \%(p<0.05)$ respectively, compared with monoculture. These results showed that with the density increase of G. parviflora, the inhibition of G. parviflora to soybean was strong. As farmland weed, G. parviflora had strong competitiveness [9-10], and higher density made more competitiveness. The same as root biomass, the shoot biomass of soybean increased when intercropping with $1 \mathrm{G}$. parviflora seedling, and decreased when intercropping with 2, 3, 4 and $5 \mathrm{G}$. parviflora seedlings compared with monoculture (Fig. $1 \mathrm{~B}$ ). The shoot biomass of soybean increased by $1.85 \%(p>0.05)$ when intercropping with 1 G. parviflora seedling, and decreased by $8.62 \%(p>$ $0.05), 30.15 \%(p<0.05), 39.08 \%(p<0.05)$ and $48.92 \%(p<0.05)$ when intercropping with $2,3,4$ and 5 G. parviflora seedlings, respectively, compared with monoculture. So, intercropping with $1 G$. parviflora seedling was benefit to promoting soybean growth.
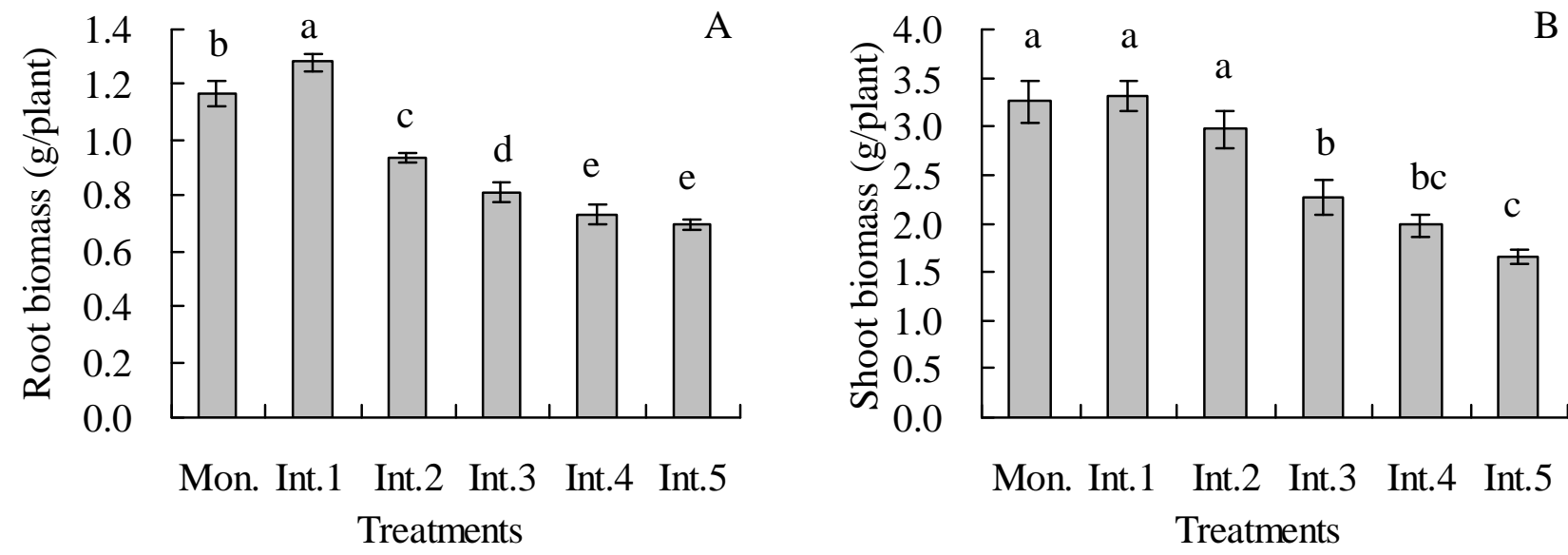

Fig. 1 Effects of intercropping density of $G$. parviflora on biomass of soybean. $\mathrm{A}=$ Root biomass, $\mathrm{B}=$ Shoot biomass. Mon. = monoculture, Int. $1=$ Intercropping with 1 G. parviflora seedling, Int. $2=$ Intercropping with $2 \mathrm{G}$. parviflora seedlings, Int.3 = Intercropping with $3 \mathrm{G}$. parviflora seedlings, Int. 4 = Intercropping with $4 \mathrm{G}$. parviflora seedlings, Int.5 = Intercropping with $5 \mathrm{G}$. parviflora seedlings.

Cd Content in Soybean. When intercropping with G. parviflora, the Cd contents in roots and shoots of soybean decreased compared with monoculture (Fig. 2 A, B). Compared with monoculture, the Cd content in roots of soybean decreased by $25.36 \%(p<0.05), 40.12 \%(p<0.05), 45.39 \%(p<$ 
$0.05), 48.65 \%(p<0.05)$ and $60.59 \%(p<0.05)$ when intercropping with 1, 2, 3, 4 and 5 G. parviflora seedlings, respectively (Fig. 2 A). The Cd content in shoots of soybean decreased by $28.20 \%(p<0.05)$, $30.82 \%(p<0.05), 38.26 \%(p<0.05), 45.49 \%(p<0.05)$ and $50.21 \%(p<0.05)$ when intercropping with 1, 2, 3, 4 and 5 G. parviflora seedlings, respectively, compared with monoculture (Fig. 2 B). As Cd-hyperaccumulator, $G$. parviflora has strong absorption ability to soil $\mathrm{Cd}$, and the number of $G$. parviflora greater in unit area, the more Cd was absorbed, which is consistent with other studies [11-12].

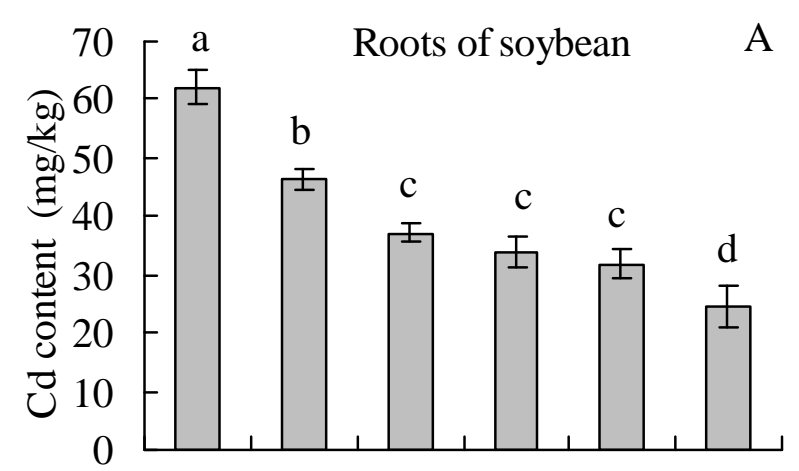

Mon. Int.1 Int. 2 Int.3 Int.4 Int.5 Treatments

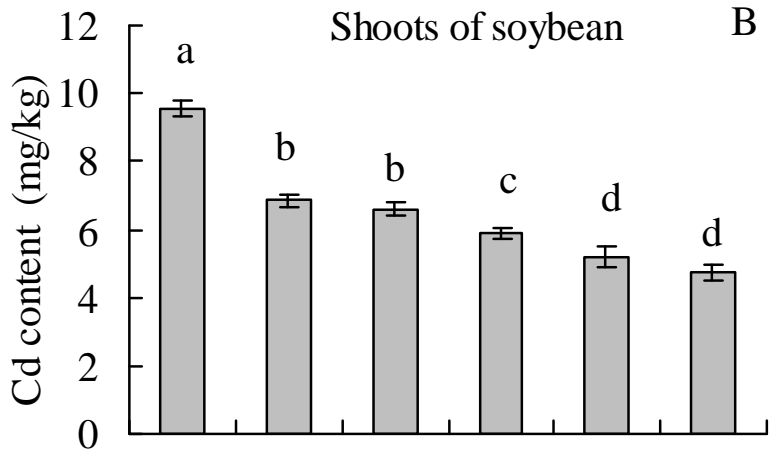

Mon. Int.1 Int.2 Int.3 Int.4 Int.5 Treatments

Fig. 2 Effects of intercropping density of $G$. parviflora on Cd content in soybean. A = Root biomass, B $=$ Shoot biomass. Mon. $=$ monoculture, Int. $1=$ Intercropping with 1 G. parviflora seedling, Int. $2=$ Intercropping with $2 \mathrm{G}$. parviflora seedlings, Int. 3 = Intercropping with $3 \mathrm{G}$. parviflora seedlings, Int. 4 = Intercropping with $4 \mathrm{G}$. parviflora seedlings, Int. $5=$ Intercropping with $5 \mathrm{G}$. parviflora seedlings.

Cd Accumulation of G. parviflora. After intercropping with soybean, with the density increasing, the root and shoot biomasses of $G$. parviflora increased when the density was not more than 3 , and decreased when the density was higher than 3 (Table 1). The Cd contents in roots and shoots of $G$. parviflora decreased when the density was not more than 3 , and decreased when the density was higher than 3 with the density increase of G. parviflora, (Table 1). The Cd content in roots of G. parviflora was ranked as: 5 G. parviflora $>1$ G. parviflora $>2$ G. parviflora $>4$ G. parviflora $>3$ G. parviflora, and the Cd content in shoots of G. parviflora was 5 G. parviflora $>4$ G. parviflora $>1$ G. parviflora $>$ $2 G$. parviflora $>3 \mathrm{G}$. parviflora. With the increase of density, the Cd exaction by roots of $G$. parviflora increased, and the Cd exaction by shoots of $G$. parviflora increased when the density was not more than 4 (Table 1). The Cd exaction by roots of G. parviflora was ranked as: 5 G. parviflora > 4 G. parviflora $>3$ G. parviflora $>2$ G. parviflora $>1$ G. parviflora, and the Cd exaction by shoots of G. parviflora was $4 \mathrm{G}$. parviflora $>5 \mathrm{G}$. parviflora $>3 \mathrm{G}$. parviflora $>2 \mathrm{G}$. parviflora $>1 \mathrm{G}$. parviflora. The maximum of Cd extraction by shoots was $469.81 \mu \mathrm{g} /$ pot. Therefore, the density of $4 G$. parviflora seedlings intercropping with soybean could remediate soil Cd effectively.

Table 1 Effects of intercropping with soybean on Cd accumulation of G. parviflora

\begin{tabular}{|l|l|l|l|l|l|c|}
\hline \multirow{2}{*}{ Treatments } & \multicolumn{2}{|c|}{ Biomass (g/plant) } & \multicolumn{2}{c|}{ Cd content $(\mathrm{mg} / \mathrm{kg})$} & \multicolumn{2}{c|}{ Cd extraction $(\mu \mathrm{g} / \mathrm{pot})$} \\
\cline { 2 - 7 } & Roots & Shoots & Roots & Shoots & Roots & Shoots \\
\hline 1 G. parviflora & $1.58 \pm 0.04 \mathrm{~b}$ & $3.65 \pm 0.21 \mathrm{~b}$ & $18.58 \pm 0.59 \mathrm{ab}$ & $26.30 \pm 0.99 \mathrm{bc}$ & $29.36 \pm 0.15 \mathrm{~d}$ & $96.00 \pm 1.96 \mathrm{e}$ \\
\hline 2 G. parviflora & $1.85 \pm 0.10 \mathrm{a}$ & $4.15 \pm 0.24 \mathrm{ab}$ & $17.55 \pm 0.64 \mathrm{ab}$ & $24.31 \pm 1.12 \mathrm{c}$ & $64.94 \pm 1.12 \mathrm{c}$ & $201.77 \pm 2.42 \mathrm{~d}$ \\
\hline 3 G. parviflora & $1.83 \pm 0.06 \mathrm{a}$ & $4.43 \pm 0.33 \mathrm{a}$ & $15.23 \pm 1.09 \mathrm{c}$ & $23.39 \pm 1.42 \mathrm{c}$ & $83.61 \pm 3.39 \mathrm{~b}$ & $310.85 \pm 3.84 \mathrm{c}$ \\
\hline 4 G. parviflora & $1.72 \pm 0.13 \mathrm{ab}$ & $4.01 \pm 0.08 \mathrm{ab}$ & $16.58 \pm 0.59 \mathrm{bc}$ & $29.29 \pm 1.71 \mathrm{ab}$ & $114.07 \pm 4.35 \mathrm{a}$ & $469.81 \pm 7.51 \mathrm{a}$ \\
\hline 5 G. parviflora & $1.24 \pm 0.08 \mathrm{c}$ & $2.64 \pm 0.19 \mathrm{c}$ & $18.99 \pm 0.81 \mathrm{a}$ & $32.30 \pm 2.40 \mathrm{a}$ & $117.74 \pm 3.06 \mathrm{a}$ & $426.36 \pm 0.24 \mathrm{~b}$ \\
\hline
\end{tabular}




\section{Conclusions}

Intercropping with $1 \mathrm{G}$. parviflora seedling increased biomass of soybean compared with monoculture, and decreased when intercropping with 2, 3, 4 and $5 \mathrm{G}$. parviflora seedlings. Intercropping with different density of $G$. parviflora decreased $\mathrm{Cd}$ content in soybean compared with monoculture, and the more number of $G$. parviflora, the lower Cd content in soybean. When the density was not more than 3, intercropping with soybean increased biomass of G. parviflora, and decreased Cd content in $G$. parviflora. Intercropping with soybean increased $\mathrm{Cd}$ extraction by $\mathrm{G}$. parviflora, and the maximum of Cd extraction by shoots of $G$. parviflora was at the density of $G$. parviflora. Therefore, the best density of $G$. parviflora to intercropping with soybean was 1 .

\section{References}

[1] C. Li, X. He, S. Zhu, H. Zhou, Y. Wang, Y. Li, J. Yang, J. Fan, J. Yang, G. Wang, Y. Long, J. Xu, Y. Tang, G. Zhao, J. Yang, L. Liu, Y. Sun, Y. Xie, H. Wang, Y. Zhu, Crop diversity for yield increase, PLoS ONE 4 (2009) e8049.

[2] Y.Y. Zhu, H.R. Chen, J.H. Fan, Y.Y. Wang, Y. Li, J.B. Chen, J.X. Fan, S.S. Yang, L.P. Hu, H. Leung, T.W. Mew, P.S. Teng, Z.H. Wang, C.C. Mundt,. Genetic diversity and disease control in rice, Nature 406 (2000) 707-716.

[3] Y.Y. Yang, J.Y. Jung, W.Y. Song, H.S. Suh, Y. Lee, Identification of rice varieties with high tolerance or sensitivity to lead, and characterization of the mechanism of tolerance, Plant Physiology 124 (2000) 1019-1026.

[4] Z.G. Shen, F.J. Zhao, S.P. McGrath, Uptake and transport of zinc in the hyperaccumulator Thlaspi caerulescences and the non-hyperaccumulator Thlaspi ochroleucum, Plant, Cell \& Environment 20 (1997) 898-906.

[5] C.J. Li, W. Ma, F.S. Zhang, Rhizosphere talk and its impacts on plant growth, Plant Nutrition and Fertilizer Science 14 (2008) 178-183 (In Chinese).

[6] C.A. Jiang, Q.T. Wu, S.H. Wu, X.X. Long, Effect of co-cropping Sedum alfredii with different plants on metal uptake, China Environmental Science 29 (2009) 985-990 (In Chinese).

[7] S.N. Whiting, J.R. Leake, S.P. McGrath, A.J. Baker, Hyperaccumulation of Zn by Thlaspi caerulescens can ameliorate $\mathrm{Zn}$ toxicity in the rhizosphere of cocropped Thlaspi arvense, Environmental science \& technology 35 (2001) 3237-3241.

[8] B. Yang, W.S. Shu, Z.H. Ye, Growth and metal accumulation in vetiver and two Sesbania species on lead/zinc mine tailings, Chemosphere 52 (2003) 1593-1600.

[9] L.J. Lin, Q. Jin, Y.J. Liu, B. Ning, M.A. Liao, L. Luo, Screening of a new cadmium hyperaccumulator, Galinsoga parviflora, from winter farmland weeds using the artificially high soil cadmium concentration method, Environmental Toxicology and Chemistry 33 (2014) 2422-2428.

[10] S.H. Wei, Q.X. Zhou, X. Wang, W. Cao, Studies on the characteristics of heavy metal hyperaccumulation of weeds in farmland, China Environmental Science 24 (2004) 105-109 (In Chinese).

[11] Y.X. Yang, X.M. Zhu, J.R. Shao, Z.B. Yang, P. Cheng, Influence of different mixed proportion on $\mathrm{Zn}$ and $\mathrm{Cd}$ enrichment of white clover and vetiver, Journal of Soil and Water Conservation 28 (2014) 266-275 (In Chinese).

[12] K.W. Huang, M.A. Liao, L.J. Lin, Effects of interplantation ratio of two ecotypes of Bidens pilosa on cadmium accumulation, Journal of Ecology and Rural Environment 31 (2015) 753-759 (In Chinese). 